\title{
Transanal Removal of Misplaced Intrauterine Contraceptive Device
}

\author{
Waleeja Shamikhaa ${ }^{1, *}$ and Yasir Makkib ${ }^{2}$ \\ ${ }^{1}$ Surgical Unit 2, Sheikh Zayed Medical Collage and Hospital, Rahim Yar Khan, Pakistan. \\ ${ }^{2}$ Peadiatric Surgery, Sheikh Zayed Medical Collage and Hospital, Rahim Yar Khan, Pakistan.
}

\begin{abstract}
Intrauterine contraceptive devices are among the most effective forms of contraceptives worldwide. However few complications have been associated with it including uterine perforation which may lead to bowel injury. This is a case of 34-year-lady who had Intra Uterine Copper Device (IUCD) placed 6 years ago. She presented with feeling of strings of IUCD through anus, low backache, and non-cyclical bleeding per rectum for last four months. On sigmoidoscopy, a Copper-T Device was found lodged in anterior rectal wall, which was successfully removed with mild traction transanally. A simple clinical examination i.e digital rectal examination followed by proctosigmoidoscopy, diagnosed and led to complete treatment of the patient, with no post-operative complications.
\end{abstract}

Keywords: IUCD complications, Uterine perforation, Rectal perforation, Sigmoidoscopy, Transanal removal. doi.org/10.21089/njhs.23.0132

\section{INTRODUCTION}

Intrauterine contraceptive devices have been used as economical and effective method of contraception, with few health risks. They include infection, uterine bleed, ectopic pregnancy and the most dire of them being uterine perforation; the incidence ranging from 1.6 / 1000 insertions [1]. Perforation is most commonly seen through the posterior wall of the uterus [2]. Patients may be asymptomatic or suffer with abdominal pain, fever, vaginal or rectal bleeding, and possibly intermittent diarrhea if bowel injury is present $[3,4]$. Perforation must also be ruled out if pregnancy occurs with an IUCD in place. Different methods have been adopted for surgical removal of IUCD, of which laparoscopy, endoscopy and laparotomy have been used. This case includes removal of IUCD per rectum with minimal manipulation and no post-operative complications.

\section{CASE}

A 34-year old lady, who previously had two normal vaginal deliveries 6 years ago, had her intrauterine copper device (IUCD) inserted for contraception in a family planning clinic. Over this period she conceived twice with normal vaginal deliveries at 2 and 4 years respectively. Patient was presented to us with complaint of feeling of thread of IUCD per rectum, mild backache and few episodes of non-cyclical bleeding per rectum for last four months.

She was investigated with ultrasound and X-rays for misplaced IUCD (Figs. 1-4).

*Address correspondence to this author at the Surgical Unit 2, Sheikh Zayed Medical Collage and Hospital, Rahim Yar Khan, Pakistan.

E-mail: waleeja.shamikha@gmail.com
Later she was referred to our surgical department for proctoscopy and sigmoidoscopy. On digital rectal examination, limbs of IUCD were palpated at $9 \mathrm{~cm}$ from anal verge. Rigid sigmoidoscopy was performed in lateral decubitus position and IUCD was detected covered with fecal matter (Fig. 5), with one of the limbs embedded in the rectal wall. It was given traction distally with a grasping forceps to dislodge it and successfully retrieved transanally. There was no significant bleeding. Patient was given analgesic and metronidazole post-removal. She was alright on follow up.

\begin{tabular}{|c|c|}
\hline \multicolumn{2}{|r|}{ Abdominal Ultrasound } \\
\hline Liver & $\begin{array}{l}\text { Is normal in size and texture, measures } 13.5 \mathrm{~cm} \text { in mid calvi- } \\
\text { cular line. No focal lesion or dilated ducts seen. }\end{array}$ \\
\hline CBD \& PV & $\mathrm{CBD}$ and $\mathrm{PV}$ are normal. $\mathrm{PV}$ measures $10 \mathrm{~mm}$. \\
\hline GB & $\begin{array}{l}\text { No stone/mass seen. Wall thickness is normal. No perichole- } \\
\text { cystic fluid collection seen. Sonographic Murphy's sign is } \\
\text { negative. }\end{array}$ \\
\hline Spleen & Is not enlarged, measures $8.8 \mathrm{~cm}$. No focal lesion seen. \\
\hline Pancreas & $\begin{array}{l}\text { is normal. No calcification seen. No peri-pancreatic fluid } \\
\text { collection. }\end{array}$ \\
\hline Kidneys & $\begin{array}{l}\text { Rt. kidney measures } 9.5 \mathrm{~cm} \text { and Left kidney measures } 10.0 \mathrm{~cm} \text {. } \\
\text { Both kidneys are normal in size and contour. Renal cortical } \\
\text { enhogenicity and corticomedullary differentiation is normal. } \\
\text { No stone or hydronesphrosis seen. }\end{array}$ \\
\hline $\begin{array}{l}\text { U. Bladder } \\
\text { Pelvic } \\
\text { Organs }\end{array}$ & $\begin{array}{l}\text { is partially filled. No stone or mass seen. } \\
\text { Retroverted normal sized uterus is noted measuring } \\
8.2 \times 3.5 \times 4.6 \mathrm{~cm} \text { with central endometrial echos measuring } \\
8 \mathrm{~mm} \text {. No uterine mass or gestational sac or RPOC's seen. } \\
\text { Both ovaries are normal in size and texture. } \\
\text { No adnexal mass or cyst seen. } \\
\text { No ascites or para-aortic lymphadenopathy noted. }\end{array}$ \\
\hline & Normal Abdomino-pelvic Study. \\
\hline
\end{tabular}

Fig. (1). Ultrasound of abdomen shows no $\mathrm{Cu}-\mathrm{T}$ in uterine cavity.

www.njhsciences.com 


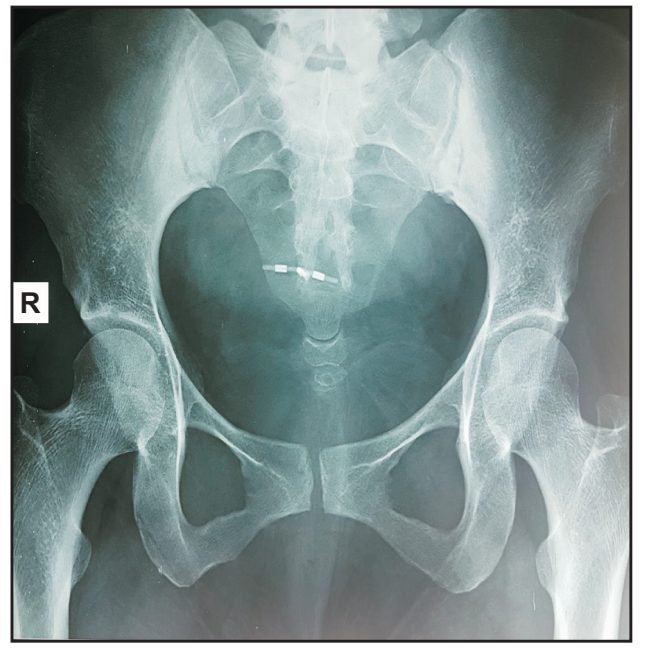

Fig. (2). X-ray pelvis shows $\mathrm{Cu}-\mathrm{T}$ in the pelvic cavity.

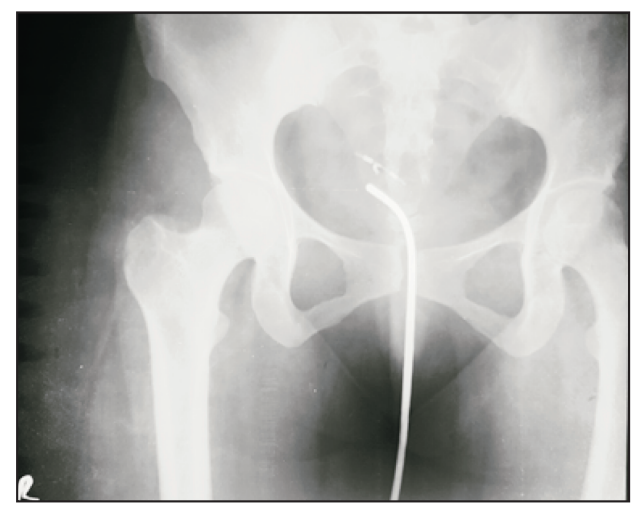

Fig. (3). X-ray pelvis AP view with uterine sound in uterine cavity showing $\mathrm{Cu}-\mathrm{T}$ outside the uterus, more towards right side of patient.

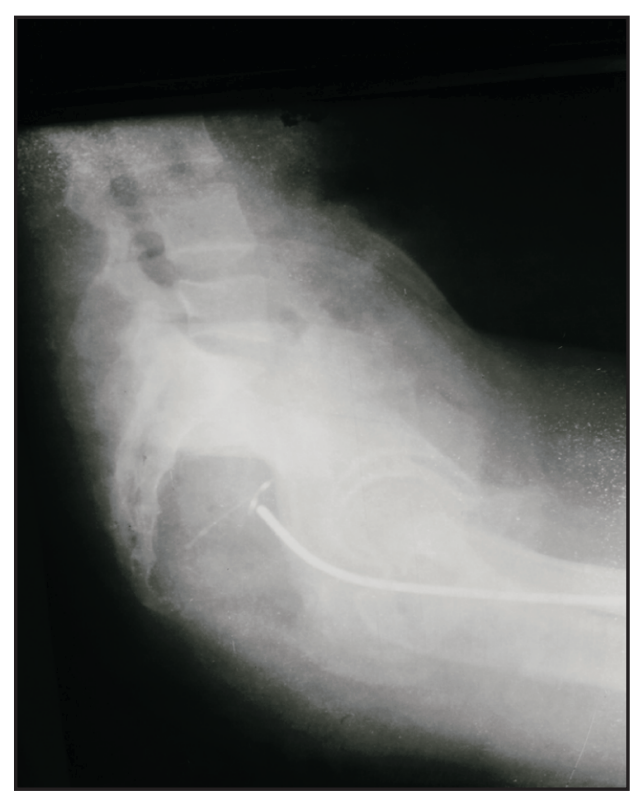

Fig. (4). Lateral view of $\mathrm{X}$-ray Abdomen shows $\mathrm{Cu}-\mathrm{T}$ in presacral space.

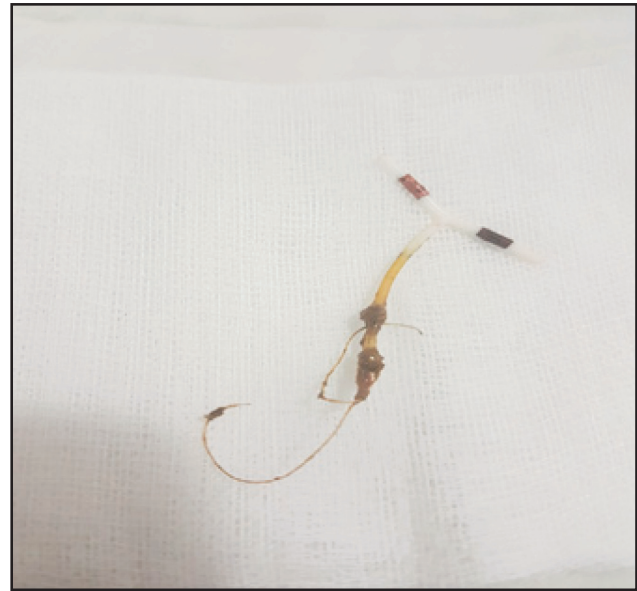

Fig. (5). Cu-T removed from rectum, covered with faecal matter.

\section{DISCUSSION}

Uterine perforation may occur upon insertion or IUCD may become embedded in the uterus and later be forced through the wall by uterine contractions into the pelvic or abdominal cavity or into adjacent organs such as the bladder, rectum, sigmoid or appendix [5]. If a patient becomes pregnant or the IUCD string is not visible at the external os, uterine perforation should be suspected. A regular self-examination for the "missing threads" should be made mandatory [7]. Withdrawal of the migrated IUCD is advisable even if its migration has not given rise to any clinical symptoms [8], so that further complications like a bowel and bladder perforation or a fistula formation may be averted. Laparoscopy, laparotomy, and now endoscopy have been successfully used to remove misplaced IUCDs: the latter, especially for removal from lower rectum and colon $[6,9,10]$. This is recommended because of the potential for bowel perforation or intestinal obstruction [1,11, 12]. The benefit of an endoscopic approach as first-line therapy is the avoidance of an operation that could require extensive dissection to the lower rectum with risk of injury to pelvic nerves and vasculature [13]. If the IUCD is amenable to endoluminal retrieval this approach may also prevent the need for a colotomy (and primary repair) or resection (and anastomosis or stoma) in order to remove the IUCD [14].

\section{CONCLUSION}

An IUCD is a safe method of contraception. Patients do present with lost or misplaced IUCDs. The health care professionals should ensure that a mere insertion of IUCD is not the end point of their services. They should also educate the clients about the potential benefits, adverse effects, complications and regular self-examination for strings of the device.

There are very few cases reporting the feeling of strings of IUCD per rectum. So, rectal examination should be included in the evaluation of patients for missing IUCDS. This may 
be followed by removal of the devices per rectum if partially embedded in its wall rather than referring to surgery. Any surgical intervention of pelvis may injure the pelvic nerves and vasculature resulting in chronic pain and worsening of misery of patient.

\section{CONFLICT OF INTEREST}

Declared none.

\section{ACKNOWLEDGEMENT}

Declared none.

\section{ETHICAL APPROVAL}

Not required.

\section{REFERENCES}

[1] Mederos R, Humaran L, Minervini D. Surgical removal of an intrauterine device perforating the sigmoid colon: a case report. Int. J. Surg., 2008; 6(6): 60-2. DOI: 10.1016/j.ijsu.2007.02.006

[2] Medina TM, Hill DA, DeJesus S, Hoover F. IUD removal with colonoscopy: a case report. J. Reprod. Med., 2005; 50(7): 547-9.

[3] Sepulveda WH, Ciuffardi I, Olivari A, Gallegos O. Sonographic diagnosis of bladder perforation by an intrauterine device: a case report. J. Reprod. Med., 1993; 38(11): 911-3.

[4] Nceboz US, Ozcakir HT, Uyar Y, Caglar H. Migration of an intrauterine contraceptive device to the sigmoid colon: a case report. Eur. J. Contracept. Reprod. Health Care, 2003; 8(4): 22932. DOI: $10.1080 /$ ejc.8.4.229.232

[5] Carson SA, Gatlin A, Mazur M. Appendiceal perforation by Copper-7 intrauterine contraceptive device. Am. J. Obstet. Gynecol., 1981; 141(6): 586-7.

DOI: 10.1016/s0002-9378(15)33284-1
[6] Ma GW, Yuen A, Vlachou PA, de Montbrun S. An unconventional therapeutic approach to a migratory IUD causing perforation of the rectum. J. Surg. Case Rep., 2016; 2016(2): rjw004. DOI: 10.1093/jscr/rjw004

[7] Johri V, Vyas KC. Misplaced intrauterine contraceptive devices: common errors; uncommon complications. J. Clin. Diagn. Res., 2013; 7(5): 905-7. DOI: 10.7860/jcdr/2013/5287.2982

[8] Treisser A, Colau JC. Causes, diagnosis and treatment of uterine perforations by intrauterine devices. J. Gynecol. Obstet. Biol. Reprod., 1978; 7(4): 837-47.

[9] Chi E, Rosenfeld D, Sokol TP. Laparoscopic removal of an intrauterine device perforating the sigmoid colon: a case report and review of the literature. Am. Surg., 2005; 71(12): 1055-7.

[10] Stuckey A, Dutreil P, Aspuru E, Nolan TE. Symptomatic cecal perforation by an intrauterine device with appendectomy removal. Obstet. Gynecol., 2005; 105: 1239-41.

DOI: 10.1097/01.aog.0000157760.59342.bc

[11] Harrison-Woolrych M, Ashton J, Coulter D. Uterine perforation on intrauterine device insertion: is the incidence higher than previously reported?. Contraception, 2003; 67(1): 53-6. DOI: 10.1016/s00107824(02)00417-1

[12] Kriplani A, Garg P, Sharma M, Agarwal N. Laparoscopic removal of extrauterine IUCD using fluoroscopy guidance: a case report. $J$. Gynecol. Surg., 2005; 21(1): 29-30. DOI: 10.1089/gyn.2005.21.29

[13] McCombie JJ, Le Fur R. Colonoscopic removal of an ectopic intrauterine device. ANZ J. Surg., 2012; 82(5): 369-70. DOI: 10.1111/j.1445-2197.2012.06031.x

[14] Gonenc M, Kalayci MU, Turhan AN, Deniztas C, Alis H. Endoscopic treatment of a transmigrated intrauterine device to colonic wall: a case report. Am. J. Obstet. Gynecol., 2011; 204(3): 3-5. DOI: 10.1016/j.ajog.2010.11.037 